\title{
A Vehicle Routing Problem with Time Windows Subject to the Constraint of Vehicles and Good's Dimensions
}

\author{
Carles Sitompul ${ }^{1}$, Octa Manasye Horas ${ }^{1 *}$ \\ ${ }^{1}$ Department of Industrial Engineering, Universitas Katolik Parahyangan, Jl. Ciumbuleuit No.94, Bandung \\ 40141, Indonesia
}

\begin{abstract}
A vehicle routing problem (VRP) can be defined as a problem finding the optimal route to minimize the travel distance, time, and cost used in a distribution process. A VRP with time windows, also known as a Time Window Priority Model (TWPM), prioritizes time windows using mathematical modeling so that vehicles would not be delayed at any point during the distribution process. Scant literature exists discussing TWPMs subject to load carrying capacity. They only consider the vehicle container volume and the volume of items being carried, arbitrarily assigning $90 \%$ of the vehicle's capacity, which leads to a large, unused capacity. The utilization of capacity, defined as the ratio of the actual weight of the items being transported to the maximum weight of the total items with full capacity, is an important factor for efficient transportation. We believe that the vehicle's capacity can be increased when considering the actual dimensions of goods (i.e., their lengths, widths, and heights), as well as the dimensions of the vehicle's containers. This study considers a three-dimensional loading constraint-length, width, and height-of both items and vehicles. Based on the study results, it can be concluded that taking into account the actual dimensions of items and containers in the capacity constraint increases the utilization of vehicles. Moreover, in some cases, the total travel distance and the total number of routes can be reduced.
\end{abstract}

Keywords: Capacity loading constraint; Three-dimensional loading constraint; Time window priority model; Vehicle routing problem;

\section{Introduction}

One of the core elements of supply chain management is managing the transportation process (Hugos, 2003; Young and Sook, 2000). Transportation or distribution can be optimized by implementing a vehicle routing problem (VRP), which is described as a problem designing an optimal delivery or collection routes from one or several depots to a number of geographically scattered cities or customers, subject to side constraints (Laporte, 1992; Cordeau et al., 2007). The main scope of the problem involves finding a set of vehicle routes (usually not fixed) that optimally visit a specific number of clients or nodes, concerning several constraints (Trachanatzi et al., 2020).

Some previous studies have been carried out to solve VRPs considering time window constraints. Wang and Wen (2020) developed an LC-2EHVRP model with a mixed timewindow, simultaneously considering economic cost, environmental issues (carbon emissions), and customer satisfaction for 3PL in cold-chain logistics and obtained an

${ }^{*}$ Corresponding author's email: octa.manasye@gmail.com, Tel.: +62-81-222437319

doi: 10.14716/ijtech.v12i4.4294 
optimal solution to deal with it. Comert et al. (2017) proposed a hierarchical approach to solving Vehicle Routing Problem with Time Windows (VRPTW) that consists of two stages: clustering and routing. In the clustering stage, customers are assigned to vehicles using three different clustering algorithms: K-means, K-medoids, and DBSCAN, with the controlling capacity of each cluster. In the routing stage, a traveling salesmen problem (TSP) is solved based on a Mixed-Integer Liner Programming (MILP) model that aims to minimize total waiting and travel times.

Kong et al. (2013) developed a VRP mathematical model called the Time Window Priority Model (TWPM). The model includes time window constraints (i.e., clients' opening and closing hours) to ensure that vehicles arrive within specific intervals during the distribution process. The model also includes another constraint on carrying capacities. The vehicle capacity constraint only considers the volume of transported items and the vehicle container volumes, arbitrarily assigning $90 \%$ of the vehicle capacity, which causes a large number of unused capacities. As such, it is necessary to consider the dimensions of both the transported items and vehicle's containers in order to define the capacity constraint, thereby increasing the container's capacity utilization. To do so, we developed a VRP with time windows subject to capacity constraints, taking into account the actual dimensions of both items and vehicles. We assumed that the problem is static and deterministic. It was also assumed that vehicles were homogeneous and the container shapes were identical. The orientation of transported items was fixed, and the vehicle routing was dedicated to a pickup service. The remainder of the paper is as follows: Section 2 discusses the methods and solution approaches to the problems. The results and discussion are presented in Section 3 , with the conclusions and further research being discussed in Section 4.

\section{Methods}

The model is developed by considering the dimensions of transported items and the dimensions of the vehicle's containers. The dimension of transported items and the dimensions of vehicle containers are used to calculate the actual total capacity. In this study, we call this model the Time Window Priority Model with three-dimensional loading constraints (TWPM with 3D loading constraints).

\subsection{TWPM with Three-Dimensional Loading Constraints}

In the TWPM developed by Kong et al. (2013), the calculation of used capacity only considers the volume of transported items and the volume of vehicle containers by which the total volume of all transported items cannot exceed the volume of vehicle containers whose value is the result of arbitrary multiplying the volume of vehicle containers with 0.9. This certainly does not provide a total value for the maximum use of vehicle container capacity. Therefore, we need a constraint that considers the dimensions of transported items in calculating the actual total capacity used. The capacity constraints are developed from the Three-Dimensional Bin Packing Problem (3D-BPP) mathematical models (Martello et al., 2000). The other 3D-BPP model development was done by Hifi et al. (2010), then solved using Linear Programming. The parameters of the mathematical model for TWPM with 3D loading constraints can be seen in Table 1.

The decision variables of the TWPM mathematical model with 3D loading constraints can be seen in Table 2 . The first decision variable $\mathrm{x}=1$ means that if the total vendor served by the $k$-th vehicle $\left(n_{k}\right)$ is more than or equal to 1 , then $\mathrm{x}=1$ and 0 means otherwise. The second decision variable means that if the total waiting time for the $i$-th vendor $\left(t u_{i}\right)$ plus the vehicle travel time from the $i$-th vendor to the $j$-th vendor $\left(t_{i j}\right)$ multiplied by 0.25 is less than the required time that the vehicle travels back and forth from the distribution center, 
then $\mathrm{y}=1$, which indicates that the vehicle must wait until the $i$-th vendor opens or starts the window time service $\left(a_{i}\right)$ or 0 , which means otherwise.

Table 1 Parameters of TWPM with 3D loading constraints

\begin{tabular}{cl}
\hline Parameters & \\
\hline$K$ & Maximum number of vehicles \\
$k$ & Maximum number of vendors \\
$i, j$ & Index of vehicle $(k=1,2, \ldots, K)$ \\
$n_{k}$ & Maximum number of vendors whose items can be picked up by the $k$-th vehicle \\
$p_{i}, l_{i}, t_{i}$ & Length, width, and height of the $i$-th vendor items \\
$P, L, T$ & Length, width, and height of the vehicle container \\
$x_{i}, y_{i}, z_{i}$ & The coordinate of the $i$-th vendor items in vehicle container \\
{$\left[a_{i}, b_{i}\right]$} & The time window of the $i$-th vendor \\
$d_{i j}$ & The distance from the $i$-th vendor to the $j$-th vendor (kilometer) \\
$d_{0 i}$ & The distance from the distribution center to the $i$-th vendor (kilometer) \\
$s_{k i}$ & The time of the $k$-th vehicle arriving at the $i$-th vendor \\
$t u_{i}$ & The waiting time of the vehicle at the $i$-th vendor (minute) \\
$t_{i j}$ & The traveling time from the $i$-th vendor to the $j$-th vendor (minute) \\
$t b_{i}$ & The loading time of the vehicle at the $i$-th vendor (minute) \\
$R_{k}$ & The set of the $k$-th route \\
$r_{k i}$ & The $R_{k}$ element, which indicates the order of vendors; $r_{k i}=0$ indicates the \\
$S_{0}$ & distribution center \\
$v$ & The time that the vehicle departures from the distribution center to the first vendor \\
& The speeds of the vehicle (kilometer $/$ hour) \\
\hline
\end{tabular}

Table 2 Decision variables of the TWPM mathematical model with 3D loading constraints

\begin{tabular}{|c|c|}
\hline No & Decision Variables \\
\hline 1 & $x=\left\{\begin{array}{c}1, n_{k} \geq 1 \\
0, \text { otherwise }\end{array}\right.$ \\
\hline 2 & $y=\left\{\begin{array}{c}1,\left(t u_{i}+t_{i j}\right) 0,25<2 t_{i 0} \\
0, \text { otherwise }\end{array}\right.$ \\
\hline 3 & $a_{\alpha \beta}=\left\{\begin{array}{c}1, \text { if } \alpha \text { th item is on the left side of } \beta \text { th item } \\
0, \text { otherwise }\end{array}\right.$ \\
\hline 4 & $b_{\alpha \beta}=\left\{\begin{array}{c}1, \text { if } \alpha \text { th item is on the right side of } \beta \text { th item } \\
0, \text { otherwise }\end{array}\right.$ \\
\hline 5 & $c_{\alpha \beta}=\left\{\begin{array}{c}1, \text { if } \alpha \text { th item is in front of } \beta \text { th item } \\
0, \text { otherwise }\end{array}\right.$ \\
\hline 6 & $d_{\alpha \beta}=\left\{\begin{array}{c}1, \text { if } \alpha \text { th item is behind } \beta \text { th item } \\
0, \text { otherwise }\end{array}\right.$ \\
\hline 7 & $e_{\alpha \beta}=\left\{\begin{array}{c}1, \text { if } \alpha \text { th item is below } \beta \text { th item } \\
0, \text { otherwise }\end{array}\right.$ \\
\hline 8 & $f_{\alpha \beta}=\left\{\begin{array}{c}1, \text { if } \alpha \text { th item is on top of } \beta \text { th item } \\
0, \text { otherwise }\end{array}\right.$ \\
\hline 9 & $p x_{i}, p y_{i}, p z_{i}=\left\{\begin{array}{c}1, \text { if the length of } i \text { th item parellel to the } x, y, z \text { axis respectively } \\
0, \text { otherwise }\end{array}\right.$ \\
\hline 10 & $l x_{i}, l y_{i}, l z_{i}=\left\{\begin{array}{c}1, \text { if the width of } i \text { th item parellel to the } x, y, z \text { axis respectively } \\
0, \text { otherwise }\end{array}\right.$ \\
\hline 11 & $t x_{i}, t y_{i}, t z_{i}=\left\{\begin{array}{c}1, \text { if the height of } i \text { th item parellel to the } x, y, z \text { axis respectively } \\
0, \text { otherwise }\end{array}\right.$ \\
\hline
\end{tabular}


The value 0.25 is the average tolerance value of the waiting time that is acceptable to all vendors. Decision variable no. 3 to no. 8 are used for determines the item position in the vehicle container. Decision variables no. 9 to no. 11 are decision variables of the components on the $\mathrm{x}, \mathrm{y}$, and $\mathrm{z}$-axis, respectively. Based on the parameters and decision variables described earlier, the objective function of the mathematical model TWPM with 3D loading constraints is as follows.

$$
\operatorname{Min} z=\sum_{k=1}^{K}\left[\sum_{i=1}^{n_{k}}\left(d_{i j}+d_{n_{k} 0}\right) x+2 \sum_{i=1}^{n_{k}} v t u_{i} y\right]
$$

The objective function of the mathematical model is to minimize the mileage which can be obtained by adding up the total distance traveled by the $k$-th vehicle, distance from the previous vendor to the current vendor $\left(d_{i j}\right)$ and from the last vendor to the distribution center $\left(d_{n_{k} 0}\right)$; the waiting time is expressed by distances obtained by multiplying waiting time $\left(t u_{i}\right)$ and vehicle speed $(v)$. Minimizing mileage is not only seen from the distance between vendors and vendors with the distribution center but also from the time window of each vendor. Vehicles must arrive within the range of these time windows (Beheshti et al., 2015). If the vehicle arrives before the time window starts, the vehicle has to wait. The time spent if the vehicle has to wait at a particular vendor will affect the vehicle's productivity in serving other vendors. Therefore, the waiting time is included in the calculation of the objective function as a penalty. The constraints of the TWPM mathematical model with 3D loading constraints can be seen in Table 3 .

Table 3 Constraints of the TWPM mathematical model with 3D loading constraints

\begin{tabular}{cc}
\hline No & Constraint \\
\hline 1 & $x_{\alpha}+p_{\alpha} p x_{\alpha}+l_{\alpha} l x_{\alpha}+t_{\alpha} t x_{\alpha} \leq P$ \\
2 & $y_{\alpha}+p_{\alpha} p y_{\alpha}+l_{\alpha} l y_{\alpha}+t_{\alpha} t y_{\alpha} \leq L$ \\
3 & $z_{\alpha}+p_{\alpha} p z_{\alpha}+l_{\alpha} l z_{\alpha}+t_{\alpha} t z_{\alpha} \leq T$ \\
4 & $x_{\alpha}+p_{\alpha} p x_{\alpha}+l_{\alpha} l x_{\alpha}+t_{\alpha} t x_{\alpha} \leq x_{\beta}+\left(1-a_{\alpha \beta}\right) M$ \\
5 & $x_{\beta}+p_{\alpha} p x_{\alpha}+l_{\alpha} l x_{\alpha}+t_{\alpha} t x_{\alpha} \leq x_{\alpha}+\left(1-b_{\alpha \beta}\right) M$ \\
6 & $y_{\alpha}+p_{\alpha} p y_{\alpha}+l_{\alpha} l y_{\alpha}+t_{\alpha} t y_{\alpha} \leq y_{\beta}+\left(1-c_{\alpha \beta}\right) M$ \\
7 & $y_{\beta}+p_{\alpha} p y_{\alpha}+l_{\alpha} l y_{\alpha}+t_{\alpha} t y_{\alpha} \leq y_{\alpha}+\left(1-d_{\alpha \beta}\right) M$ \\
8 & $z_{\alpha}+p_{\alpha} p z_{\alpha}+l_{\alpha} l z_{\alpha}+t_{\alpha} t z_{\alpha} \leq z_{\beta}+\left(1-e_{\alpha \beta}\right) M$ \\
9 & $z_{\beta}+p_{\alpha} p z_{\alpha}+l_{\alpha} l z_{\alpha}+t_{\alpha} t z_{\alpha} \leq z_{\alpha}+\left(1-f_{\alpha \beta}\right) M$ \\
10 & $a_{\alpha \beta}+b_{\alpha \beta}+c_{\alpha \beta}+d_{\alpha \beta}+e_{\alpha \beta}+f_{\alpha \beta} \geq 1$ \\
11 & $0 \leq n_{k} \leq L$ \\
12 & $\sum_{k=1}^{K} n_{k}=L$ \\
13 & $x_{k 1}$ \\
14 & $R_{k}=\left\{r_{k i} \mid r_{k i} \in\{1,2, \ldots, L\}, i=1,2, \ldots, n_{k}\right\}$ \\
15 & $R_{k 1} \cap R_{k 2}=\varphi, \forall k 1 \neq \forall k 2$ \\
16 & $\left.t u_{i}=\max _{k i}+t a_{i}-s_{i}, 0\right\}$ \\
17 & $a_{i} \leq s_{k i} \leq b_{i} \cdot p_{i} \cdot l_{i} \cdot t_{i}+t_{i j}$ \\
\hline
\end{tabular}

Constraints 1 to 3 are the constraints ensuring that the items fit in the vehicle container. Constraints 4 to 10 are the constraints ensuring that the items do not overlap. The appearance of the overlapping items can be seen in Figure 1. 


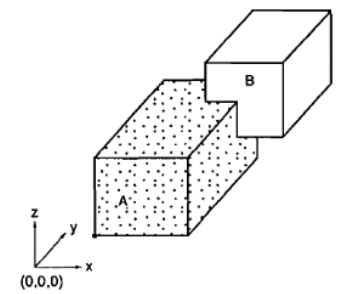

Figure 1 Overlapping items. From Three-Dimensional Palletization of Mixed Boxes, by Tsai et al. (1993)

Constraint 11 shows that the total number of vendors served by the $k$-th vehicle $\left(n_{k}\right)$ does not exceed all vendors $(L)$. Constraint 12 shows that the total number of vendors served by all vehicles $\left(\sum_{k-1}^{K} n_{k}\right)$ is equal to the total number of all vendors $(L)$. Constraint 13 shows that a set of $k$-th routes consist of consecutive vendors $\left(r_{k i}\right)$. Constraint 14 shows that the vendors served on route set 1 are not the same or intersect with those served on route set 2 . Constraint 15 shows that the waiting time for vehicles at the $i$-th vendor $\left(t u_{i}\right)$ depends on the time the $k$-th vehicle arrives at the $i$-th vendor $\left(s_{k i}\right)$ and the starting time of vendor's time window $\left(a_{i}\right)$. Constraint 16 shows that the time the $k$-th vehicle reaches the next vendor $\left(s_{k i}\right)$ is equal to the time the vehicle arrives at the previous vendor $\left(s_{k j}\right)$ plus the waiting time at the previous vendor $\left(t u_{i}\right)$ plus the loading time at the previous vendor which can be obtained by multiplying $t b_{i}$ by the volume of the vendor's item $(p \times l \times t)$ plus the travel time from the previous vendor to the next vendor $\left(t_{i j}\right)$. Constraint 17 shows that the vehicle has to arrive between the vendor's time window.

TWPM with three-dimensional loading constraints has been proposed for solving the VRP with capacity and time window constraints, which emphasize the constraint related to capacity used by considering the dimensions of transported items so as to increase the capacity utilization of the container. The introduced model is motivated by the unused capacity issues of the original TWPM model that caused the utilization of capacity to not be maximized; capacity utilization is an important factor for efficient transportation.

\subsection{Heuristic Approach}

The heuristic approach used in solving problems based on a mathematical model TWPM with 3D loading constraints can be seen below.

1. Find the vendor with the earliest closing hours based on its time window and name the vendor as $i$.

2. Find the vendor with the next earliest closing hours based on its time window and name the vendor as $j$.

3. Calculate the required time for the vehicle to arrive $\left(s_{k j}\right)$ from vendor $i$ to vendor $j$. The value of $\left(s_{k j}\right)$ is obtained from $s_{k j}=s_{k i}+p_{i}+t_{i j}$. The time the vehicle arrives at the previous vendor $\left(s_{k i}\right)$ is added up with the previous vendor's service time $\left(p_{i}\right)$ and added up with the travel time from vendor $i$ to vendor $j\left(t_{i j}\right)$.

4. Compare the time the vehicle arrives $\left(s_{k j}\right)$ with the vendor's opening hours $\left(a_{j}\right)$ and closing hours $\left(b_{j}\right)$. If $b_{j} \geq s_{k j} \geq a_{j}$, it is meet the requirement of the time window constraint.

5. Calculate the used capacity of the vehicle container by comparing the dimensions of transport items (length, width, and height of the transport items) with the dimensions of the vehicle container (length, width, and height of the vehicle container). If $\sum_{i=1}^{n_{k}} p_{i} \leq$ $P, \sum_{i=1}^{n_{k}} l_{i} \leq L$, and $\sum_{i=1}^{n_{k}} t_{i} \leq T$ simultaneous are fulfilled, insert the vendor to the present route and then repeat steps 2 to 5 . 


\section{Results and Discussion}

In order to determine the difference in the results between the TWPM mathematical model and TWPM with 3D loading constraints, calculations are made using two mathematical models. Data required for the calculations consist of the vendor's dimensions and volume of items transported, dimensions and volume of vehicle containers, travel time between vendors, and vendor time windows. The vehicle container volume was $48.07 \mathrm{~m}^{3}$ ( $9.5 \mathrm{~m}$ length $\times 2.3 \mathrm{~m}$ width $\times 2.2 \mathrm{~m}$ height). The distance between vendors in matrix form can be seen in Table 4.

Table 4 Distance matrix $(\mathrm{km})$

\begin{tabular}{ccccccc}
\hline Vendor & 0 & 1 & 2 & 3 & 4 & 5 \\
\hline 0 & - & 23.2 & 19.3 & 8.1 & 7.7 & 36.3 \\
1 & 23.2 & - & 22.1 & 21.8 & 21.4 & 17 \\
2 & 19.3 & 22.1 & - & 11.2 & 10.9 & 36.7 \\
3 & 8.1 & 21.8 & 11.2 & - & 1.8 & 35.1 \\
4 & 7.7 & 21.4 & 10.9 & 1.8 & - & 34.3 \\
5 & 36.3 & 17 & 36.7 & 35.1 & 34.3 & - \\
\hline
\end{tabular}

Each vendor consists of one or more items. The dimensions of transported items include the length, width, height, and vendor's time window, as shown in Table 5.

Table 5 Dimension of vendor's item

\begin{tabular}{ccccccccc}
\hline Vendor & $\begin{array}{c}\text { Height } \\
(\mathrm{m})\end{array}$ & $\begin{array}{c}\text { Width } \\
(\mathrm{m})\end{array}$ & $\begin{array}{c}\text { Length } \\
(\mathrm{m})\end{array}$ & $\begin{array}{c}\text { Item's } \\
\text { Volume }\left(\mathrm{m}^{3}\right)\end{array}$ & $\begin{array}{c}\text { Total } \\
\text { Items }\end{array}$ & $\begin{array}{c}\text { Total Volume } \\
\left(\mathrm{m}^{3}\right)\end{array}$ & $\begin{array}{c}\text { Opening } \\
\text { Hour }\end{array}$ & $\begin{array}{c}\text { Closing } \\
\text { Hour }\end{array}$ \\
\hline 1 & 0.73 & 1.15 & 8.49 & 7.13 & 3 & 21.38 & $8: 39$ & $9: 54$ \\
2 & 0.66 & 0.57 & 0.77 & 0.29 & 1 & 0.29 & $09: 19$ & $11: 56$ \\
3 & 0.73 & 1.15 & 9.04 & 7.62 & 3 & 22.86 & $09: 40$ & $11: 38$ \\
4 & 2.00 & 0.57 & 6.72 & 7.66 & 1 & 7.66 & $10: 02$ & $10: 31$ \\
5 & 1.10 & 1.15 & 8.66 & 10.95 & 2 & 21.9 & $08: 47$ & $10: 36$ \\
\hline
\end{tabular}

The travel time (in matrix form) required for vehicles to move from one vendor to another can be seen in Table 6.

Table 6 Travel time matrix (min)

\begin{tabular}{ccccccc}
\hline Vendor & 0 & 1 & 2 & 3 & 4 & 5 \\
\hline 0 & - & 28 & 23 & 10 & 9 & 44 \\
1 & 28 & - & 27 & 26 & 26 & 20 \\
2 & 23 & 27 & - & 13 & 13 & 44 \\
3 & 10 & 26 & 13 & - & 2 & 42 \\
4 & 9 & 26 & 13 & 2 & - & 41 \\
5 & 44 & 20 & 44 & 42 & 41 & - \\
\hline
\end{tabular}

\subsection{Optimal Solutions}

We developed an AMPL model and solved the problem using the CPLEX engine to find optimal solutions. The routing results using the TWPM mathematical model can be seen in Table 7. 
Table 7 TWPM routing results

\begin{tabular}{cccc}
\hline Route & Distance $(\mathrm{km})$ & Capacity $\left(\mathrm{m}^{3}\right)$ & Total Distance $(\mathrm{km})$ \\
\hline $0-4-3-2-0$ & 20.7 & 30.81 & \\
$0-1-0$ & 23.3 & 21.38 & 80.3 \\
$0-5-0$ & 36.3 & 21.9 & \\
\hline
\end{tabular}

The routing results using the TWPM mathematical model with 3D loading constraints can be seen in Table 8.

Table 8 TWPM with three-dimensional loading constraints routing results

\begin{tabular}{cccc}
\hline Route & Distance $(\mathrm{km})$ & Capacity $\left(\mathrm{m}^{3}\right)$ & Total Distance $(\mathrm{km})$ \\
\hline $0-1-5-0$ & 40.3 & 43.28 & \multirow{2}{*}{60.9} \\
$0-4-3-2-0$ & 20.7 & 30.81 & \\
\hline
\end{tabular}

\subsection{Heuristic Results}

For larger problems, we developed a greedy heuristic approach described as follows. The results obtained using this approach can be seen in Table 9.

1. Find the vendor with the earliest closing hours based on its time window and name that vendor $i$.

The vendor with the earliest closing hours is vendor 1.

2. Find the vendor with the next earliest closing hours based on its time window and name that vendor $j$.

The vendor with the next earliest closing hours is vendor 4.

3. Calculate the required time for the vehicle to arrive $\left(s_{k j}\right)$ from vendor $i$ to vendor $j$.

The total time required for the vehicle to go from vendor 1 to vendor 4 is 58 minutes, obtained by adding up the time the vendors were served, 32 minutes, and the travel time from vendor 1 to vendor 4, 26 minutes. The vehicle arrived at vendor 1 at 09:07 and will arrive at vendor 4 at 10:05.

4. Compare the time the vehicle arrives $\left(s_{k j}\right)$ within the vendor's opening hours $\left(a_{j}\right)$ and closing hours $\left(b_{j}\right)$.

The vehicle's arrival time at vendor 4 is between the vendor's time window, which meets the requirement of the time window constraint.

5. Calculate the used capacity of the vehicle container.

Capacity calculations are done by comparing the dimensions of transport items and the dimensions of the vehicle container simultaneously.

Table 9 Routing and item placement result

\begin{tabular}{ccccc}
\hline Vendor & Item & $\begin{array}{c}\text { Length }(\mathrm{m}) \\
\text { (x-axis) }\end{array}$ & $\begin{array}{c}\text { Width (m) } \\
\text { (y-axis) }\end{array}$ & $\begin{array}{c}\text { Height }(\mathrm{m}) \\
\text { (z-axis) }\end{array}$ \\
\hline \multirow{2}{*}{1} & 1 & 8.49 & 1.15 & 0.73 \\
& 2 & 8.49 & 1.15 & 1.46 \\
4 & 3 & 8.49 & 1.15 & 2.19 \\
\hline
\end{tabular}

6. Repeat steps 2 through 5.

If the time window constraint, as well as the dimensions of transport items and the dimensions of the vehicle container constraints, are met, then the vendor is included in 
the route; repeat Steps 2 to 5 . The final results of the route, along with the placement of the transport items, can be seen in Table 10.

Table 10 Routing and item-placement complete results

\begin{tabular}{|c|c|c|c|c|c|c|c|c|}
\hline Route & Vendor & Item & $\begin{array}{l}\text { Length (m) } \\
\quad \text { (x-axis) }\end{array}$ & $\begin{array}{c}\text { Width (m) } \\
\text { (y-axis) }\end{array}$ & $\begin{array}{l}\text { Height (m) } \\
\text { (z-axis) }\end{array}$ & $\begin{array}{c}\text { Capacity } \\
\left(\mathrm{m}^{3}\right)\end{array}$ & $\begin{array}{l}\text { Distance } \\
(\mathrm{km})\end{array}$ & $\begin{array}{c}\text { Total } \\
\text { Distance } \\
(\mathrm{km})\end{array}$ \\
\hline \multirow{5}{*}{1} & & 1 & 8.49 & 1.15 & 0.73 & \multirow{5}{*}{29.33} & \multirow{5}{*}{55.5} & \multirow{10}{*}{126.9} \\
\hline & 1 & 2 & 8.49 & 1.15 & 1.46 & & & \\
\hline & & 3 & 8.49 & 1.15 & 2.19 & & & \\
\hline & 4 & 1 & 6.72 & 1.72 & 2 & & & \\
\hline & 2 & 1 & 0.77 & 2.29 & 0.66 & & & \\
\hline \multirow{5}{*}{2} & & 1 & 8.66 & 1.15 & 1.1 & \multirow{5}{*}{44.76} & \multirow{5}{*}{71.4} & \\
\hline & 5 & 2 & 8.66 & 1.15 & 2.2 & & & \\
\hline & \multirow{3}{*}{3} & 1 & 9.04 & 2.3 & 0.73 & & & \\
\hline & & 2 & 9.04 & 2.3 & 1.46 & & & \\
\hline & & 3 & 9.04 & 2.3 & 2.19 & & & \\
\hline
\end{tabular}

Figure 2 is a visual example of the placement of transport items of routes 1 and 2 based on results using the heuristic method.

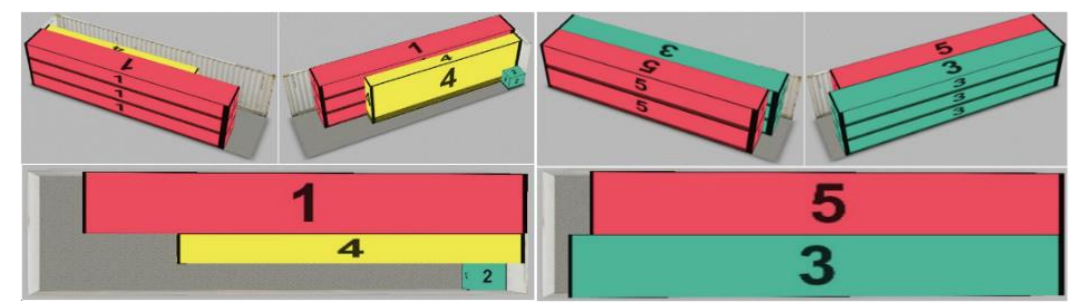

(a)

(b)

Figure 2 Visualization of transport items placement of: (a) route 1; and (b) route 2

\subsection{Comparison of Optimal Solution and TWPM Heuristic Results with Three-Dimensional Loading Constraints}

According to Table 11, the comparison results between the optimal solution and TWPM heuristic approach with 3D loading constraints can be seen from the results of the total distance. The time limit and optimality gap set in CPLEX were default and equaled $1 \mathrm{e}^{75}$ seconds and 0 , respectively. CPLEX could solve the problem to optimality in 0.0625 seconds.

Table 11 Optimal solution and heuristic results comparison

\begin{tabular}{|c|c|c|c|c|c|}
\hline & $\begin{array}{c}\text { Number of } \\
\text { Route }\end{array}$ & $\begin{array}{l}\text { Transported Volume } \\
\text { Average }\left(\mathrm{m}^{3}\right)\end{array}$ & $\begin{array}{l}\text { Loading Rate } \\
\text { Average }\end{array}$ & $\begin{array}{l}\text { Total Distance } \\
(\mathrm{km})\end{array}$ & $\begin{array}{c}\text { Vehicle } \\
\text { Container } \\
\text { Volume }\left(\mathrm{m}^{3}\right)\end{array}$ \\
\hline $\begin{array}{l}\text { Optimal solution } \\
\text { Heuristic approach }\end{array}$ & $\begin{array}{l}2 \\
2\end{array}$ & $\begin{array}{l}37.045 \\
37.045\end{array}$ & $\begin{array}{l}77.06 \% \\
77.06 \%\end{array}$ & $\begin{array}{c}60.9 \\
126.9\end{array}$ & 48.07 \\
\hline
\end{tabular}

\subsection{Test of Significance Results}

The significance test was used to see whether there is a significant difference between the objective function results obtained using the TWPM mathematical model and TWPM with 3D loading constraints. The data used in the significance test were obtained from the results of objective function from 30 cases, calculated using the CPLEX engine, and each case consisted of 5 vendors. A recapitulation of the results can be seen in Table 12 . 
Table 12 Results recapitulation

\begin{tabular}{cccccccc}
\hline & $\begin{array}{c}\text { Distance } \\
\text { of } \\
\text { TWPM } \\
\text { Results } \\
(\mathrm{km})\end{array}$ & $\begin{array}{c}\text { Distance of TWPM } \\
\text { with 3D Loading } \\
\text { Constraints Results } \\
(\mathrm{km})\end{array}$ & Difference & & $\begin{array}{c}\text { Distance } \\
\text { of } \\
\text { TWPM } \\
\text { Results } \\
(\mathrm{km})\end{array}$ & $\begin{array}{c}\text { Distance of TWPM } \\
\text { with 3D Loading } \\
\text { Constraints Results } \\
(\mathrm{km})\end{array}$ & Difference \\
\hline 1 & 80.3 & 61 & -19.3 & 16 & 85.9 & 73.7 & -12.2 \\
2 & 99.7 & 90.1 & -9.6 & 17 & 71.4 & 69.7 & -1.7 \\
3 & 81.9 & 74 & -7.9 & 18 & 103.6 & 101.5 & -2.1 \\
4 & 73.2 & 54.4 & -18.8 & 19 & 101.4 & 94.3 & -7.1 \\
5 & 66.3 & 53.6 & -12.7 & 20 & 67.8 & 66.7 & -1.1 \\
6 & 64.7 & 58.7 & -6 & 21 & 78.9 & 74.7 & -4.2 \\
7 & 81 & 76.3 & -4.7 & 22 & 92.9 & 85.2 & -1.1 \\
8 & 76.4 & 71.3 & -5.1 & 23 & 102.8 & 101.7 & -9.8 \\
9 & 64.5 & 53.9 & -10.6 & 24 & 66.1 & 56.3 & -3.3 \\
10 & 70.4 & 69.3 & -1.1 & 25 & 73.1 & 55.3 & -21 \\
11 & 71.9 & 58.6 & -13.3 & 26 & 122.2 & 118.9 & -16 \\
12 & 72.7 & 59.6 & -13.1 & 27 & 77.1 & 56.1 & -7.8 \\
13 & 123.3 & 109.5 & -13.8 & 28 & 63.6 & 47.6 & -14.8 \\
14 & 90.9 & 52.9 & -38 & 29 & 47.5 & 39.7 & \\
15 & 67.2 & 66.1 & -1.1 & 30 & 67.3 & 52.5 & \\
\hline
\end{tabular}

Before the significance test, the normality test was first conducted to determine the difference between the two samples because the requirement for the significance test was a normally distributed difference between the two samples. Table 13 is the result of the normality test from the difference between the two samples.

Table 13 Normality test

\begin{tabular}{lrrrrr}
\hline & \multicolumn{4}{c}{ Kolmogorov-Smirnova } \\
\cline { 2 - 6 } & Statistic & df & Sig. \\
\hline Difference & & .130 & & 30 & $.200^{*}$ \\
\hline
\end{tabular}

The significance value (Sig.) $=0.2 \geq \alpha$, can be concluded that the distance difference is normally distributed. Table 13 is the result of the significance test. The significance test used is the paired t-test because data comes from the same sample with different treatments (Kim, 2015). In this case, different treatments are the calculation of the distance using the TWPM mathematical model and TWPM with 3D loading constraints.

Table 14 Paired t-test

\begin{tabular}{|c|c|c|c|c|c|c|c|c|c|}
\hline & & \multirow[t]{2}{*}{ Mean } & \multirow{2}{*}{$\begin{array}{c}\text { Std. } \\
\text { Deviation }\end{array}$} & \multirow{2}{*}{$\begin{array}{l}\text { Std. Error } \\
\text { Mean }\end{array}$} & \multicolumn{2}{|c|}{$\begin{array}{c}95 \% \text { Confidence Interval } \\
\text { of the Difference }\end{array}$} & \multirow[t]{2}{*}{$\mathrm{t}$} & \multirow[t]{2}{*}{$\mathrm{df}$} & \multirow{2}{*}{$\begin{array}{l}\text { Sig. }(2 \\
\text { tailed })\end{array}$} \\
\hline & & & & & Lower & Upper & & & \\
\hline Pair 1 & $\begin{array}{l}\text { Model } 1 \text { - } \\
\text { Model } 2\end{array}$ & 10.09333 & 7.99547 & 1.45977 & 7.10778 & 13.07889 & 6.914 & 29 & .000 \\
\hline
\end{tabular}

The significance value (Sig.) $=0<\alpha$; thus, it can be concluded that there is a significant difference between the distance obtained from calculations using the TWPM mathematical model and TWPM with 3D loading constraints. 


\subsection{Comparison of the Mathematical Model of TWPM and TWPM with Three-Dimensional Loading Constraints}

The comparison between the TWPM mathematical model and TWPM with 3D loading constraints can be seen from the results of the objective function. In addition, the average volume of transport served by a vehicle can also be used to compare the mathematical model results.

Table 15 Results of the TWPM mathematical model and TWPM with three-dimensional loading constraints comparison

\begin{tabular}{cccccc}
\hline & $\begin{array}{c}\text { Number of } \\
\text { Route }\end{array}$ & $\begin{array}{c}\text { Transported Volume } \\
\text { Average }\left(\mathrm{m}^{3}\right)\end{array}$ & $\begin{array}{c}\text { Loading Rate } \\
\text { Average }\end{array}$ & $\begin{array}{c}\text { Distance } \\
\text { Average }(\mathrm{km})\end{array}$ & $\begin{array}{c}\text { Vehicle Container } \\
\text { Volume }\left(\mathrm{m}^{3}\right)\end{array}$ \\
\hline Model 1 & 6 & 34.78 & $72.35 \%$ & 105.33 & 48.07 \\
Model 2 & 5 & 41.822 & $87.00 \%$ & 138.6 & 48.07 \\
\hline
\end{tabular}

Model 1 indicates the TWPM mathematical model; Model 2 indicates the TWPM mathematical model with 3D loading constraints. The number of routes based on Table 14 was reduced from six to five. In addition, in some cases, the number of routes could be the same, or the number of routes generated by the TWPM mathematical model with 3D loading constraints could be increased. Although the number of routes was the same or even increased, the results of total mileage were different. The total mileage generated using the TWPM mathematical model with 3D loading constraints was further. The average transported volume increased by applying the TWPM mathematical model with 3D loading constraints.

\section{Conclusions}

Based on the results of mathematical calculations and analyses, several conclusions can be drawn: (1) This study aimed to TWPM propose a model that considered the actual dimensions of items and containers in the capacity constraints, namely, TWPM with 3D loading constraints. The TWPM mathematical model with 3D loading constraints can solve the trip-route determination problem. The constraints that must be considered include the time window constraint for each vendor as well as the dimensions of transport items and vehicle container constraints (length, width, and height) of each vendor; (2) The results of the TWPM mathematical model with 3D loading constraints were proven to increase the capacity utilization of vehicle containers and reduce the total travel distance; (3) This study assumed that vehicles used to solve the routing problem are homogeneous; hence, routing using a heterogeneous vehicles should be considered in future research.

\section{References}

Beheshti, A.K., Hejazi, S.R., Alinaghian, M., 2015. The Vehicle Routing Problem with Multiple Prioritized Time Windows: A Case Study. Computers \& Industrial Engineering, Volume 90, pp. 402-413

Comert, S.E., Yazgan, H.R., Sertvuran, I., Sengul, H., 2017. A New Approach for Solution of Vehicle Routing Problem with Hard Time Window: An Application in A Supermarket Chain. Sadhana, Volume 42(12), pp. 2067-2080

Cordeau, J.F., Laporte, G., Savelsbergh, M.W., Vigo, D., 2007. Vehicle Routing. In: Handbook in OR \& MS 2007, Barnhart and Laporte (eds.), ELSEVIER, Philadelphia 
Hifi, M., Kacem, I., Negre, S., Wu, L., 2010. A Linear Programming Approach for the ThreeDimensional Bin-Packing Problem. Electronics Notes in Discrete Mathematics, Volume 36(2010), pp. 993-1000

Hugos, M., 2003. Essentials of Supply Chain Management. USA: John Wiley \& Sons, Inc.

Kim, T.K., 2015. T Test as A Parametric Statistic. Korean Journal of Anesthesiology, Volume 68(6), pp. 540-546

Kong, J., Jia, G., Gan, C., 2013. A New Mathematical Model of Vehicle Routing Problem Based on Milk-Run. In: International Conference on Management Science and Engineering 20th Annual Conference Proceedings

Laporte, G., 1992. The Vehicle Routing Problem: An Overview of Exact and Approximate Algorithms. European Journal of Operational Research, Volume 59(3), pp. 345-358

Martello, S., Pisinger, D., Vigo, D., 2000. The Three-Dimensional Bin Packing Problem. Operations Research, Volume 48(2), pp. 256-267

Trachanatzi, D., Rigakis, M., Marinaki, M., Marinakis, Y., 2020. A Firefly Algorithm for the Environmental Prize Collecting Vehicle Routing Problem. Swarm and Evolutionary Computation, Volume 57, 100712

Tsai, R.D., Malstrom, E.R., Kuo, W., 1993. Three Dimensional Palletization of Mixed Box Sizes. IIE Transactions, Volume 25(4), pp. 64-75

Wang, Z., Wen, P., 2020. Optimization of a Low-Carbon Two-Echelon Heterogeneous-Fleet Vehicle Routing for Cold Chain Logistics under Mixed Time Window. Sustainability, Volume 12(5), pp. 1-22

Young, H.L. Sook, H.K., 2000. Optimal Production-Distribution Planning in Supply Chain Management using a Hybrid Simulation-Analytic Approach. In: 2000 Winter Simulation Conference Proceeding, Orlando, FL, USA 